\title{
TRADITIONAL AND ONLINE FACULTY MEMBERS' USE OF CLASSROOM ASSESSMENT TECHNIQUE (CATS): A MIXED-METHOD STUDY*
}

\author{
Manyu Li, University of Louisiana at Lafayette \\ Sandi van Lieu, Grand Canyon University
}

\begin{abstract}
The goal of this study is to investigate both the prevalence and the described strategies of university professors' use of one of the Scholarship of Teaching and Learning (SoTL) techniques, Classroom Assessment Techniques (CATS). This study also aims to compare whether traditional and online faculty and full-time and part-time faculty differ in their use of CATs. Through mixed methodologies, both statistics of the use of CATs (quantitative) and actual experiences described by faculty (qualitative) were reported. In Study 1, 117 university faculty were recruited for the survey study and all but five of them used some forms of CATs (97\%) and about two-third of them indicated using CATs "often" or "always" (70\%). No significant differences were found between adjunct and full-time faculty. No difference was found between faculty teaching online and in the traditional classroom. In Study 2, five adjunct faculty were recruited to participate in an interview study and descriptions of their experiences of the use of CATs were obtained and analyzed. Several themes were identified to address how CATs were used and why faculty supported the use of CATs. Implications for faculty training and future studies were discussed.
\end{abstract}

Keywords: Scholarship of Teaching and Learning, SoTL, Classroom Assessment Technique, Adjunct, online teaching, university education

*This is part of the project being funded by the Scholarship of Teaching and Learning (SoTL) Research Grant, awarded by the Society of the Teaching of Psychology, American Psychological Association Division 2.

\section{INTRODUCTION}

Since Boyer's (1990) classic book on the scholarship of teaching, research on the Scholarship of Teaching and Learning (SoTL) has flourished, evidencing that it benefits students' learning process (e.g., Trigwell, Martin, Benjamin, \& Prosser, 2000). Using a mixed-method design, the goal of this study was to investigate the prevalence of the use of one of the SoTL techniques, Classroom Assessment Techniques (CATs), by university faculty. This study also aimed to compare whether traditional and online faculty and full-time and part-time faculty differ in their use of CATs. Through mixed methodologies, we reported both statistics of the use of CATs (quantitative) and the actual experiences described by faculty (qualitative). We expect that this study will increase the understanding of the current state of SoTL in university settings by exploring the frequency and experiences of faculty use of SoTL. Through increasing awareness of SoTL and specifically CATs, the results will have implications for faculty training of SoTL. 


\section{THE THEORETICAL BACKGROUND OF CATS}

CATs were theorized and put forward by Angelo and Cross (1993). They defined CATs as formal assessments or a set of activities that involve both teachers and students that require teachers to apply the feedback collected from the students to their teaching-learning process (Angelo \& Cross, 1993). Through CATs, faculty are able to collect timely responses from students and make adjustments to their teaching (Angelo $\&$ Cross, 1993). CATs were found to have various benefits for students, such as an increase in class participation, student engagement (Steele \& Dyer, 2014), and learning outcomes (Arundell \& Cioffi, 2005). Because of the benefits, CATs are one of the strategies recommended by the APA Board of Educational Affairs in psychology education (American Psychological Association, 2016).

CATs are also consistent with the Commitment-Trust Theory (Morgan \& Hunt, 1994)researchers, and students discover, use, and build upon a wide range of content in a trusted digital archive. We use information technology and tools to increase productivity and facilitate new forms of scholarship. For more information about JSTOR, please contact support@jstor.org. Relationship marketing-establishing, developing, and maintaining successful relational exchangesconstitutes a major shift in marketing theory and practice. After conceptualizing relationship marketing and discussing its ten forms, the authors (1. The Commitment-Trust Theory was originally a marketing theory suggesting that when customers feel their needs are being heard, they are more likely to build trust and commit to a business. Applying this to the teacher-student relationship, the CATs, which encourage the teachers to hear the students' feedback, are likely to be helpful in increasing trust between teachers and students and increasing students' commitment to learning.

Although teacher-student relations are different from the relations between business and customer, there are some similarities. For example, both types of relationships require mutual communication, and research has shown that the mutual communication between teachers and students contribute to students' learning (Chen, 2000). Also, both relationships involve one giver (of services, products, or knowledge) and one receiver. In business, the giver or service provider may create a sense of brand loyalty (i.e., consistent positive responses to the service provider) or belongingness (Chaudhuri \& Holbrook, 2001). Similarly, a positive environment supported by the teaching community may encourage students to feel attached and that they belong to the school, which in turns, increase academic motivation (Li, Frieze, Nokes-Malach, \& Cheong, 2013). Research describes teacherstudent relations to be one of a giver and receiver (e.g., Chesebro, 2003; Ellis, 2004). In addition, the Commitment-Trust Theory is often applied to the educational setting (e.g., teachers' commitment to students, Lee, Zhang, \& Yin, 2011; students' trust to teachers, Hennig-Thurau, Langer, \& Hansen, 2001).

\section{The Prevalence of CATs by Faculty Types}

Research on SoTL is flourishing, yet studies that specifically look at the prevalence and experiences of teachers' use of CATs are limited. A Google Scholar search of the literature on "classroom assessment" yielded 44,200 articles, among which 13,700 were conducted within the last five years. However, most of these publications are books, chapters, or articles that provide suggestions to teachers without any empirical data to back them up. When the results were narrowed down to empirical articles, studies usually focused on one group of teachers (e.g., grade school or university) mainly in the traditional classroom, and if the study involved higher education, it usually focused on one particular major (e.g., nursing or neuroscience, and so forth). For example, a study looking at the prevalence of classroom assessment in primary school teachers indicated that the mean of teachers' classroom assessment literary, on average, was only 17.11 points out of the 35-point possible (Yamtim \& Wongwanich, 2014). However, according to the search, there seemed to be no studies conducted in the United States that looked at the prevalence of CATs by university faculty. In addition, it is important to examine and compare adjuncts versus full-time faculty and faculty who teach in traditional classrooms versus online classrooms. Therefore, the present study not only considers university faculty population but also different types of university faculty members. It is expected that such a study will increase our understanding of the current state of the use of SoTL (specifically CATs) and will have implications for future faculty 
training.

\section{Importance of Considering Adjuncts}

Over the last several decades there has been a growth in adjuncts teaching psychology and other subjects at two- and four-year institutions (Mazurek, 2011; Weir, 2011). Most of this growth has been because of increased student enrollment and budget cuts (Gappa \& Leslie, 1993).Although more psychology students are being educated by adjuncts, the adjuncts were found to lack motivation in applying active and collaborative methods in the classroom (Baldwin \& Wawrzynski, 2011). The field of higher-education research is also calling for the inclusion of adjuncts (Kezar \& Sam, 2010). Therefore, we use a survey to quantitatively look at the prevalence of the use of CATs in adjunct faculty and compare the findings between adjuncts and full-time faculty.

\section{Importance of Considering Online Faculty}

Another focus of this study is to look at the prevalence of the use of CATs in faculty teaching in online versus the traditional classroom. Similar to research on adjuncts, research on online teaching strategies is limited. Research suggested that students learn better when online teachers are not only present but are also active in developing a positive connection between teachers and students (Mastel-Smith, Post, \& Lake, 2015). This kind of caring presence was suggested to encourage sharing and bonding (Covington, 2003). CATs, which encouraged communication between teachers and students, are particularly vital in an online setting. Understanding how online teachers use CATs is important. Therefore, we will use the survey to quantitatively look at the prevalence of online faculty use of CATs and compare the findings between online and traditional faculty.

In addition to understanding how prevalent faculty are in using CATs and what differences exist between adjunct and full-time faculty and between online and traditional faculty, we conducted through mixed methods a semistructured interview study to identify how faculty describe their experiences using different CAT-related strategies. The results will fill gaps in the field in several ways: (1) instead of focusing on a single type of faculty, we compared different types of university faculty on their use of a CATs, which will have implications for faculty training at different levels; (2) the use of mixed-method strategies will yield new insights in SoTL research; and (3) the focus on the rising yet unrepresented adjuncts and online population will add new knowledge to the field of SoTL.

\section{STUDY 1}

To investigate how prevalent faculty members use of CATs is and whether different types of faculty (online vs. traditional or part time vs. full time) differed in their use of CATs, a quantitative survey study was conducted. The research questions were:

1. What is the percentage of all faculty who use CATs?

2. What are the differences in the use of CATs, if any, between adjunct faculty and fulltime faculty?

3. What are the differences in the use of CATs, if any, between online faculty and faculty teaching in traditional classroom?

\section{Method}

Procedure. Data were collected through two means. Faculty were invited through an email announcement using a faculty listserv of one institution in the southwestern United States. However, this institute also has a large presence of online faculty who do not reside in the region. The study description and consent form were attached to the email. Participants were not paid due to university policy. A study announcement was also distributed through email to faculty outside this institute. To maintain consistency across both groups, these participants were not paid either. Participants who were interested clicked through the Qualtrics survey link provided in the email. Participants then read a consent form that informed their rights and potential minimal risk. The participants indicated their consent to participate by clicking the "next" button on the first page of the online survey. Participants then completed a brief online survey (approximately five minutes). After completing the survey, participants were given a debriefing form with the explanation of the purpose and anticipated results of the study. No compensation was given to the participants.

Sample. A total of 117 four-year university faculty members were recruited. Among the participants, most were adjunct faculty $(\mathrm{N}=85$, $73 \%$ ). Half of them were online faculty who did not teach in a traditional classroom $(\mathrm{N}=51,44 \%)$, and half of them were faculty who mostly taught 
in traditional classrooms, though some may also teach in the online classroom. About half of the faculty participants indicated they were female $(\mathrm{N}=67,57 \%)$. The disciplines that the faculty taught were mainly psychology-related subjects $(\mathrm{N}=44)$ and the rest were education $(\mathrm{N}=15)$, business $(\mathrm{N}=13)$, science $(\mathrm{N}=5)$, humanities $(\mathrm{N}$ $=11)$, and health care $(\mathrm{N}=14)$. To test if majors were related to the use of CATs, the majors were recategorized into psychology-related majors and nonpsychology-related majors. Because the sample size of some majors was too small for meaningful comparison. An ANOVA result showed that there was no significant difference between faculty teaching psychology-related (the majority group) and nonpsychology-related majors.

Measures. Engagement in CATs was measured by asking how often participants perform ten different CAT activities listed in Angelo and Cross (1993), rated on a Likert scale from 1 (never) to 5 (always). A description of each technique and a definition of a CAT was provided to participants. The description was taken from Angelo and Cross (1993). Appendix A shows the list of CATs described to participants. One additional question on other CAT strategies was included to capture any missed CAT activities. To compute their CAT engagement score, the above items were averaged to form a mean score. Cronbach's alpha of the scale was 0.8 , showing a good reliability of the scale.

Participants were also asked to indicate whether they were an adjunct faculty or full-time faculty. One participant indicated that he had multiple adjunct appointments that made a full-time job. However, because of the nature of the position he held, this person was coded as adjunct faculty instead of full time. Participants were also asked to indicate whether they were teaching online, in the traditional classroom, or both. Data were recoded so that "online" referred to people who had some teaching done in an online classroom (i.e., both "online" and "both" response), and "traditional" referred to people who did not have any online teaching component. Demographic data, such as age, type of institution, courses taught, and years of experiences, were collected.

\section{Results}

Prevalence of the use of CATs. R statistical software was used to answer the research questions. First, frequencies and means of faculty participants' CAT engagement score were obtained. Results showed that all but five reported having used some kind of CAT $(\mathrm{N}=112,97 \%)$. Among those who had used CATs, about two-thirds of the sampled faculty participants expressed using at least one CAT "often" or "always" ( $\mathrm{N}=82,70 \%)$. The rest of the faculty participants used it only "sometimes" $(\mathrm{N}=30,26 \%)$.

Types of Faculty. Two separate ANOVAs were conducted to test whether full-time and adjunct faculty differed in their use of CATs (i.e., their CAT engagement score) and whether online and traditional classroom faculty were different in their use of CATs. However, the use of CATs was found to be unrelated to the employment status of the faculty members (full time vs. part time) or classroom settings (traditional vs. online). Among the demographic variables, only years of teaching experiences were found to be positively correlated

Table 1. Means and Standard Deviations of CAT Use

\begin{tabular}{|l|l|l|}
\hline & \multicolumn{1}{|c|}{ Mean } & SD \\
\hline \multicolumn{3}{|c|}{ Classroom setting N.S. } \\
\hline Online (N=52) & 2.24 & .86 \\
\hline Traditional (N=52) & 2.02 & .71 \\
\hline \multicolumn{3}{|c|}{ Employment status N.S. } \\
\hline Full-time (N=19) & 2.13 & .77 \\
\hline Part-time (N=85) & 2.13 & .80 \\
\hline
\end{tabular}


with the use of CATs $(\mathrm{r}=.22, p<.05)$. Table 1 showed the means and standard deviation by types of faculty.

\section{Conclusion of Study 1}

Our findings from Study 1 indicated that most faculty were knowledgeable of CATs and used some kind of CAT. Most faculty often or always used CATs in their classroom. However, employment status and classroom settings did not seem to relate to their use of CATs. In our study, we found that the more a faculty member has taught, the more likely he or she uses CATs.

\section{STUDY 2}

Study 1 showed that within our sample, types of faculty members were not different in terms of whether they used CATs or not. Also, it appeared that they were knowledgeable and engaged in using CATs. However, it is still unknown how the faculty use CATs (i.e., the description of the strategies) and why they choose to use CATs. Faculty members sometimes use CATs because of institutional requirements. Understanding how and why they used CATs could show us how motivated (instead of only how prevalent) faculty are in using CATs. Therefore, in the follow-up qualitative study, we addressed the research questions (1) how faculty apply CATs and (2) why faculty choose to use CATs. In this study, we selected one particular group of faculty, adjunct psychology, to avoid possible confusion. We expected through this semistructured interview to obtain a greater understanding of their described experiences of using CATs.

\section{Method}

Procedure. We conducted semistructured interviews with psychology adjuncts either in person or via an online technology that interview lasted approximately 15 minutes. Participants were recruited through an email announcement using a faculty listserv of one institution in southwestern United States. Because we were interested in how faculty applied CATs, this purposive sampling aimed to reach out to faculty who were knowledgeable about CATs. Adjuncts agreeing to participate were scheduled for an interview with the second author. Because the institution does not permit researchers to pay participants, no reimbursement was given to interview participants.
Once a participant agreed to participate, the interviewer and the participant met via the video conference tool Zoom. Participants were then presented with a consent form. All interviews were recorded, but no personal information was obtained and faces were obscured. Participants were then asked questions pertinent to (1) their knowledge of CATs (e.g., Do you know what Classroom Assessment Techniques are? If so, how do you recall learning about them?), and (2) how often they use CATs in classrooms and what types of CATs they use (e.g., Do you utilize CATs in your classroom? Why or why not?). Follow-up questions were also developed to tap into the details of the participants' responses.

The data from the interviews were transcribed and then read and reread for immersion. The researchers then utilized a structural coding method to conduct a first-cycle round of coding (Saldana, 2013). After this, the second round of coding was conducted using In Vivo coding (Saldana, 2013). The final coded data that emerged were used to answer the qualitative research questions: (1) how do faculty use CATs in their classroom and (2) why faculty use CATs.

Sample. Five psychology adjuncts were recruited to participate in the semistructured interview. All participants were adjunct faculty teaching psychology. Two participants only taught online courses (Participants C and D), but the other three participants taught both traditional and online classes (Participants A, B, and E). All participants reported using CATs in every class, and the participants were all knowledgeable about CATs. All participants indicated they received CAT training from their institutions.

\section{Results}

Research question 1: How do faculty use CATs in classrooms? To answer our first research question, how do faculty use CATs in their classroom, we identified several strategies:

Relating theories to students' daily lives. One strategy that was commonly used was to use CATs to relate the studied topic to students' daily lives. For example,
I teach the personality psychology class and we were talking about Freud. So I just gave you the example. I asked the class, "Does venting your aggression by 
playing video games make you feel better?" ... Then I had them look at a video by Bushman and see what has changed... And then I asked them to take a moment, think about how you and others around you deal with anger, then discuss how you and others around you . . . And it was a great discussion question because people were able to relate to how first others dealt with anger and then how you dealt with anger. And so it worked out really well. That's how I used it. -Participant A

Last year, if you remember, Volkswagen was criticized for an ethics problem. And in my industrial organization class, we had some discussion on ethics and behavior ... So I will look for things that relate to ideas in psychology with the experiences people have had with the real-life events. - Participant $B$

Ice breaking. Participants also expressed that they used CATs at the beginning of the class to break the ice. For example,

And the opening question is a chance for us to get to know each other rather rapidly and learn something about our speaking style. It serves . . . as an ice-breaking discussion. - Participant $B$

Muddiest point/Tickets-out-the-door. Another strategy that participants expressed using the most was the muddiest point, that is, a method to assess what difficulties the students are having in understanding the content (Angelo \& Cross, 1993).

And I've found that the best is just a direct question... "What was the most important thing you learned during this class?" or, "What important questions remain unanswered?" that kind of, "What is the muddiest point?" - Participant A

So I open all my cohort classes with a oneminute writing exercise. I find it pretty hard to just keep it to one minute. Sometimes, it might be two minutes, two and a half minutes. But I'll do a one-minute writing exercise, and then from there, I'll ask them what they wrote down, what did they share, and try to chronicle what my students know, and deepen the discussion from that ... I like the one-minute writing exercise. I do that with every face-to-face class. I will also launch a discussion on what was muddy in our discussion, what do we need to review over again. - Participant $B$

I do a lot of question and answer because I'm doing it online. So I'll specifically look at students' questions and individualize it and then when we ask them about, "What's your background knowledge on this?" . . . The CATs I use the most often-I always ask them, "What's the muddiest point?" or, "Which part of this module did you enjoy the most?" - Participant C

I use the take-it-out-the-door the most. I actually get them a physical ticket that looks like a ticket and they write on it. And it's anonymous, and I collect that before they leave. So in order to get out the door, they have to complete it and hand it over. If they can't think of anything, I ask them just to provide a comment of some kind, which is also helpful. - Participant E

Pro/Con list. Participants also expressed using a pro/con list when the discussion question related to the discussion of advantages and disadvantages. For example,

I looked at some of the other ones, like making a . . little boxes . . (interviewer: like the pro/con list?) yeah, and have them come back with it. - Participant A

We did pros and cons-a pro and con grid where we would present a hot topic such as-it could be genetic engineering. And so the students would think about the pros of the topic and the cons of the topic and we would discuss it. That was something that was very successful. We actually turned it into a workshop. So the pro and con grid. - Participant E

Beyond CATs. In addition to the established CATs, some participants also expressed that they went beyond CATs and individualized their teaching strategies. For example, 
It's not just the CAT, answering discussion questions and responding to that. I've added something different. I've found that it brings in some of my personality. Participant A

They (CATs) just don't generate a lot of conversation. It's like they answer the questions. That's it. So what I did was, I would just develop these questions that would have the CATs buried in there and then ask another question to see if they really were getting the concept. - Participant D

Online vs. Traditional classroom. Because our samples contained both online and traditional classroom instructors, we also asked if they found the use of CATs to be different in traditional versus the online classroom. The participants expressed they used similar strategies with only minor differences. For example,

No (no difference between online and traditional classroom). But I'll tell you what . . . the online environment gives the opportunity for everyone to explain. I sometimes handed out questions to use CATs in the classrooms for students to answer but if you just try to have a conversation with it you would get the same ones that always participate, then the same ones who don't, don't answer. - Participant $C$

Research question 2: Why do faculty use CATs? To answer our second research question, why do faculty use CATs, we identified some perceived purposes or reasons behind the use of CATs by the faculty participants:

Understanding students' progress. All participants expressed that they used CATs because they wanted to know more about students' current understanding. For example,

(CAT) lets me know which students have stopped participating in class. So if I don't see them answering the CAT, I pretty much know they're not in . . (the) online classor they're not showing up to class ... So it's another indicator. - Participant A

CATs . . create more of an understanding of what students mind about, what they are assessing, and what they already know. I think the CAT techniques are an excellent way for provoking deeper thought with a student. - Participant B

I use them (CATs) all the time in my classroom because I want to see the knowledge that my students are gaining and I want to make sure that they're able to relate the topic and understand the topic. -Participant $C$

Correcting students' misconceptions/lesson plan. Related to the last factor, participants also felt that through understanding students' progress, they could correct students' misconception in time and could change their lesson plan to meet the needs of the students. For example,

There was a discussion once in which we were talking about children with ADHD, and I asked a question of the students, "Well, do you think there could be any other diagnoses beside ADHD?" And they were like, "Oh no" ... So then I thought "You know what? I need to pool the information on this because they are not aware of this. . . . They found it very enlightening. Participant D

I do (use CATs) because I don't want to wait until the end to find out that they weren't getting it. So, it's better to learn along the way. It also helps you improve your lesson plan. If you know what's working you can expand on that. If you find out what's not working, get rid of it during the class, not after. - Participant E

Conclusion of Study 2

Study 2 successfully tapped into the described experiences of faculty members who were psychology adjuncts in the southwestern United States and taught either online or in both online and traditional classrooms. These faculty participants were also unusual because they received training in CATs and were knowledgeable about CATs. Our findings indicated that the strategies that faculty like the most (and used the most) were (1) relating theories to the students' daily lives, (2) icebreaking, (3) muddiest point/ticket-out-the-door, 
and (4) pro/con list. Our study also looked into why faculty members chose to use CATs. We identified that they used CATs because it helps them (1) understand students' progress and (2) correct students' misconception early on or make changes to the lesson plan.

\section{DISCUSSION}

Our study took together quantitative and qualitative results to understand the prevalence of faculty use of CATs, the differences between types of faculty and classrooms, and how and why they use CATs. Our results showed that faculty, especially with training received from their institutions, frequently used CATs in their classroom. In addition, through Study 2, we found that these engaged faculty not only routinely use CATs, but they also used them consciously to understand students and improve their teaching.

Our results may have significant implications for faculty training. For example, Study 2 indicated that faculty who used CATs were better able to understand students' progress. In other words, being able to improve teaching qualities is what attracted these engaged faculty members to use CATs. Therefore, in future training, universities can emphasize this benefit and attract faculty to use CATs in their teaching.

In addition, our study may have implications for training specifically designed for adjuncts or online classrooms. Our sample included faculty who had online teaching experiences as well as those who were adjuncts. This population is often understudied despite their rising population in university education. Our findings seem to suggest that this special teaching population is similar to traditional faculty. However, their experiences can be very different. For example, in the interview responses we collected, faculty participants often made reference to whether a method was used in the online classroom or traditional classroom. This indicated that adjustments need to be made when they use CATs in traditional versus online classrooms.

Although the project did not solely measure development, our study may also have implications for future quantitative studies of SoTL. Specifically, the measurement we used to assess faculty engagement in CATs could be very helpful for future researchers in the field to measure how frequently they use SoTL.

Our study also has limitations. Specifically, our sample was drawn from an institution that offered CAT training and support. Therefore, our sample may be biased toward the high end of CAT users (i.e., more knowledgeable). This ceiling effect is probably why we did not find significant differences between online and traditional classroom or between adjunct and full-time faculty. More data needs to be collected to generalize to other faculty. However, in the quantitative study, we also recruited participants nationwide, which helped reduce the problems of the lack of external validity.

In conclusion, using mixed methodologies, our understanding of the prevalence of faculty use of CATs and the differences between types of faculty and classrooms, and how and why faculty use CATs, was increased. In addition, Study 2 further described how engaged faculty members applied CATs in their classrooms. Future studies may extend the present study to a larger faculty population in the United States and globally. Specifically, our sample mostly taught psychologyrelated subjects, followed by an approximately equal number of education, business, science, humanities, and health care. Future studies may extend this by recruiting a much larger sample to test the differences among different disciplines. Similarly, our sample came from four-year colleges only, which may limit the generalizability of our findings. To further understand how different types of institutions and their requirements influence the use of CATs, future studies may include samples from various types of institutions. In addition to increasing samples, future studies may look at the motivating factors (antecedents) and students' outcome (consequences) of faculty engagement in CATs. Finally, future studies may also extend to other types of SoTL. For example, if faculty members do not use CATs specifically, that may not mean they are not motivated to develop teaching strategies. Instead, they may use other preferred teaching strategies. Therefore, future studies may extend by examining alternative teaching strategies. 


\section{REFERENCES}

American Psychological Association. (2016). Applying assessment strategies in psychology: Critique of assessment strategies applied to goals and outcomes. Retrieved from http://www. apa.org/ed/governance/bea/assess-critique.aspx

Angelo, T. A., \& Cross, K. P. (1993). Classroom assessment techniques: A handbook for college teachers (2nd ed.). San Francisco, CA: Jossey-Bass.

Arundell, F., \& Cioffi, J. (2005). Using a simulation strategy: An educator's experience. Nurse Education in Practice, 5(5), 296-301. doi:10.1016/j.nepr.2005.03.001

Baldwin, R. G., \& Wawrzynski, M. R. (2011). Contingent faculty as teachers: What we know; what we need to know. American Behavioral Scientist, 55(11), 1485-1509. doi:10.1177/0002764211409194

Boyer, R. (1990). The regulation school: A critical introduction. New York, NY: Columbia University Press.

Chaudhuri, A., \& Holbrook, M. B. (2001). The chain of effects from brand trust and brand affect to brand performance: The role of brand loyalty. Journal of Marketing, 65(2), 81-93. doi:10.1509/jmkg.65.2.81.18255

Chen, Z. J. (2000). The impact of teacher-student relationships on college students' learning: Exploring organizational cultures in the classroom. Communication Quarterly, 48(2), 76-83.

Chesebro, J. L. (2003). Effects of teacher clarity and nonverbal immediacy on student learning, receiver apprehension, and affect. Communication Education, 52(2), 135-147. doi:10.1080/03634520302471

Covington, H. (2003). Caring presence: Delineation of a concept for holistic nursing. Journal of Holistic Nursing, 21(3), 301-317. doi:10.1177/0898010103254915

Ellis, K. (2004). The impact of perceived teacher confirmation on receiver apprehension, motivation, and learning. Communication Education, 53(1). doi:10.1080/0363452032000135742

Gappa, J. M., \& Leslie, D. W. (1993). The invisible faculty: Improving the status of part-timers in higher education. San Francisco, CA: Jossey-Bass Inc.

Hennig-Thurau, T., Langer, M. F., \& Hansen, U. (2001). Modeling and managing student loyalty: An approach based on the concept of relationship quality. Journal of Service Research, 3(4), 331-344. doi:10.1177/109467050134006
Kezar, A., \& Sam, C. (2010). Special issue: Understanding the new majority of non-tenure-track faculty in higher education: Demographics, experiences, and plans of action. ASHE Higher Education Report, 36(4), 1-133. doi:10.1002/ aehe.3604

Lee, J. C., Zhang, Z., \& Yin, H. (2011). A multilevel analysis of the impact of a professional learning community, faculty trust in colleagues and collective efficacy on teacher commitment to students. Teaching and Teacher Education, 27(5), 820-830. doi:10.1016/J.TATE.2011.01.006

Li, M., Frieze, I. H., Nokes-Malach, T. J., \& Cheong, J. (2013). Do friends always help your studies? Mediating processes between social relations and academic motivation. Social Psychology of Education, 16(1), 129-149. doi:10.1007/s11218012-9203-5

Mastel-Smith, B., Post, J., \& Lake, P. (2015). Online teaching: "Are you there, and do you care?" Journal of Nursing Education, 54(3), 145-151. doi:10.3928/01484834-20150218-18

Mazurek, R. A. (2011). Academic labor is a class issue: Professional organizations confront the exploitation of contingent faculty. Journal of Workplace Rights, 16(3-4), 353-366. doi:10.2190/WR.16.3-4.f

Morgan, R. M., \& Hunt, S. D. (1994). The Commitment-Trust Theory of relationship marketing. Source Journal of Marketing, 58(3), 20-38.

Saldana, J. (2013). The coding manual for qualitative researchers (2nd ed.). Thousand Oaks, CA: SAGE Publications Ltd.

Steele, J., \& Dyer, T. (2014). Use of KWLs in the online classroom as it correlates to increased participation. Journal of Instructional Research, 3, 8-14.

Trigwell, K., Martin, E., Benjamin, J., \& Prosser, M. (2000). Scholarship of Teaching: A model. Higher Education Research \& Development, 19(2), 155-168. doi:10.1080/072943600445628

Weir, K. (2011). The new academic job market. Washington, DC: American Psychological Association. Retrieved from http:// www.apa.org/gradpsych/2011/09/job-market.aspx

Yamtim, V., \& Wongwanich, S. (2014). A study of classroom assessment literacy of primary school teachers. ProcediaSocial and Behavioral Sciences, 116, 2998-3004. doi:10.1016/j.sbspro.2014.01.696 


\section{Appendix A. List of CATs Described to Participants in Study 1 (survey) Based on Angelo and Cross (1993)}

Minute paper-e.g., asking students to answer on a paper: "What is the most important point you learned today?"; and, "What point remains least clear to you?" The purpose is to elicit data about students' comprehension of a particular class session.

Muddiest point —asking students to jot down a quick response to one question: "What was the muddiest point in [the lecture, discussion, homework assignment, film, etc.]?" The term "muddiest" means "most unclear" or "most confusing."

The Background Knowledge Probe - a short, simple questionnaire given to students at the start of a course or before the introduction of a new unit, lesson, or topic. It is designed to uncover students' preconceptions.

What's the Principle? - provides students with a few problems and asks them to state the principle that best applies to each problem.

One-sentence summary-challenges students to answer the questions "Who does what to whom, when, where, how, and why?" (represented by the letters WDWWWWHW) about a given topic and then to synthesize those answers into a simple informative, grammatical, and long summary sentence.

Pro/con grid-asking students to write quick lists of pros and cons of an issue.

Student generated test questions-collecting written feedback about what students think are the most important concepts discussed in lecture.

Classroom opinion pool-having students respond through an anonymous written poll on material they will encounter in the course.

Goal rethinking and matching - having students list/rank goals and match these to instructor goals.

Chain notes-having students respond to a question written by the instructor on a large envelop that is passed around the class. The purpose is to provide feedback about what he or she noticed about the teaching and learning, engagement and involvement, occurring at a given moment during a class session. 